1 Doutoranda em Saúde Coletiva pela Universidade do Estado do Rio de Janeiro (Uerj) - Rio de Janeiro (RJ), Brasil.

dannylacer@ig.com.br

2 Doutor em Saúde Coletiva pela Universidade do Estado do Rio de Janeiro (Uerj) - Rio de Janeiro (RJ) Brasil. Professor adjunto da Universidade do Estado do Rio de Janeiro (Uerj) - Rio de Janeiro (RJ), Brasil. pharodrigues@gmail.com

\section{Política, atenção primária e acesso a serviços de Média e Alta Complexidade em pequenos municípios}

\author{
Policy, primary care and access to Medium and High Complexity \\ services in small municipalities
}

Daniela Lacerda Santos $\mathbf{1}$, Paulo Henrique de Almeida Rodrigues ${ }^{2}$

RESUMO O artigo analisa o encaminhamento de pacientes de pequenos municípios para serviços de saúde de Média ou Alta Complexidade. Nos pequenos municípios, as instituições políticas do clientelismo e do mandonismo interferem no encaminhamento dos pacientes, sendo importante inquirir como estas instituições condicionam o acesso dos pacientes da saúde da família de pequeno município àqueles serviços. Foi realizado um estudo de caso qualitativo, usando o referencial do neoinstitucionalismo histórico, entrevistas, observação assistemática, análise documental e de dados quantitativos sobre a rede de serviços e a população. Os resultados mostraram que a oferta insuficiente de serviços facilita a intermediação clientelista dos mesmos.

PALAVRAS-CHAVE Política; Atenção Primária à Saúde; Acesso aos serviços de saúde.

\begin{abstract}
The article analyzes the referral of patients from small municipalities to medium or high complexity health services. In the small municipalities, political institutions related to patronage and bossism interfere in the forwarding of patients, being considered important to question how these institutions condition the access of family health's patients from small municipalities to those services. A qualitative case study was conducted, using the reference of the historical neo-institutionalism, interviews, non-systematically observation, documentary analysis and quantitative data about the service network and the population. The results have shown that the insufficient supply of services facilitates their clientelistic intermediation.
\end{abstract}

KEYWORDS Politics; Primary Health Care; Health services accessibility. 


\section{Introdução}

Este artigo discute os resultados de pesquisa realizada no Estado de Minas Gerais sobre as condições de acesso a serviços de Média e Alta Complexidade (MAC) por parte de usuários do Sistema Único de Saúde (SUS), moradores de pequenos municípios. A grande maioria dos municípios brasileiros é de pequeno porte: mais de $2 / 3$ deles têm menos de 20 mil habitantes; quase $90 \%$ têm menos de 50 mil habitantes e, em ambos os casos, as populações dos mesmos são insuficientes para justificar a existência, por exemplo, de um hospital geral, com capacidade para atender casos de emergência e realizar cirurgias, ou mesmo um ambulatório de especialidades, só podendo oferecer serviços de Atenção Básica ou primária (RODRIGUES; SANTOS, 2011). Por não disporem destes serviços, os pequenos municípios necessitam encaminhar seus usuários para centros maiores - muitas vezes, distantes -, o que dificulta e encarece o encaminhamento de pacientes para serviços de MAC do SUS. Em Minas Gerais, onde foi realizado o estudo, havia, em 2010, 676 municípios com menos de 20 mil habitantes, ou $79,2 \%$ do total (BRASIL, 2011).

Desde sua origem remota - os Conselhos Locais de Portugal, que serviram de modelo no período colonial -, os municípios brasileiros constituem a base do sistema de poder político no Brasil. As câmaras locais daquela época eram formadas pelos chamados 'homens-bons' - em geral, os proprietários de terra mais poderosos. Desde então, o sistema político-eleitoral se assenta sobre os municípios, o que assegurou imensa influência política para os grandes proprietários de terra. Durante a Primeira República (1889-1930), o poder local no Brasil foi muito marcado pelo coronelismo, que se desenvolveu sobre as bases da antiga Guarda Nacional criada no Império (IZECKSOHN, 2009). Os coronéis em geral, grandes fazendeiros e líderes do poder local - apoiavam os governadores na garantia dos votos locais e estes davam suporte ao domínio local dos coronéis, que influenciavam na escolha dos ocupantes dos cargos públicos e controlavam, na prática, o processo eleitoral (LEAL, 1997; CARVALHO, 1997). As características secundárias do sistema coronelista são: mandonismo; clientelismo; filhotismo ou apadrinhamento; e manipulação eleitoral. Tais elementos contribuíram para prejudicar os serviços públicos locais, muitas vezes desorganizados e inoperantes (LEAL, 1997; CARVALHO, 1997).

O mandonismo local sempre fez parte de um sistema de poder oligárquico mais amplo, organizado no nível dos estados. $\mathrm{Na}$ Primeira República, a Constituição de 1891 dava liberdade aos estados para "organizarem os municípios na feição que melhor lhes parecesse" (FAORO, 2001, P. 704). Isso fazia parte da essência da "política dos governadores", que constituiu a base do sistema de dominação até 1930 (ZIMMERMAN, 1999, P. 309). Esse sistema de dominação oligárquico nunca foi totalmente desmontado, apesar das diversas transformações históricas passadas pelo País, inclusive os dois longos períodos de dominação autoritária e centralizadora (1930-1945 e 1964-1985). O sistema político-eleitoral resultante, por não contar com distritos eleitorais, obriga os candidatos a cargos eletivos estaduais e federais a buscarem votos em todo o território dos estados, dependendo de sua capacidade de estabelecer alianças locais em diversos municípios para obterem sucesso nas eleições, que, nos menores municípios, têm de ser feitas, em geral, com forças políticas tradicionais de caráter conservador (LEAL, 1997; RODRIGUES, 2011).

Segundo Nunes (2010), a dominação clientelista de base local permanece no Brasil e continua se articulando com as outras formas de dominação política, ou 'gramáticas', como ele denomina. Além da gramática do clientelismo, as outras seriam as do corporativismo - surgido da revolução de 1930 -, do insulamentoburocrático-influênciadeburocracias especializadas e poderosas em organizações estatais influentes - e do universalismo de 
procedimentos - tentativa de implantar um sistema de dominação baseado nas leis, na democracia e fundado no reconhecimento dos direitos de cidadania. Segundo ele, a dominação política no Brasil atual é uma conjugação dessas quatro instituições ou gramáticas políticas, que interagem entre si, prevalecendo uma ou outra em momentos e regiões diferentes. $\mathrm{O}$ atual 'presidencialismo de coalizão', conceito cunhado por Abranches (1988 APUD LIMONGI, 2006) para explicar a necessidade de formação de amplas coalizões políticas, para viabilizar os governos após a redemocratização de 1985, pode ser interpretado como um resultado dessa mescla das gramáticas políticas. Pode-se dizer que as políticas sociais instituídas pela Constituição de 1988, inclusive o SUS, estão no campo do universalismo de procedimentos. Sua implantação e funcionamento, entretanto, são influenciadas pelas outras gramáticas. A partir da redemocratização do País, iniciada em 1985, houve grande fortalecimento dos municípios, que passaram a dispor de maior autonomia e assumiram papel mais definido do que os estados na distribuição das atribuições governamentais particularmente, na área social -, como foi o caso da saúde (ZIMMERMANN, 1999; RODRIGUES, 2011).

O federalismo brasileiro seria marcado por uma complexa trama de coalizões, onde os interesses de elites regionais cumprem um papel muito importante. Os interesses regionais e as características e forças que dominam essas coalizões políticas condicionam o gasto público (ARRETCHE; RODDEN, 2004). A necessidade dessas coalizões torna o partido governante refém das mesmas e gera um complexo método de negociação em torno do processo decisório, marcado por mecanismos políticos voltados para a formação de maioria no Congresso Nacional. Tais mecanismos são, essencialmente, a distribuição dos cargos no Executivo e a barganha legislativa em torno da utilização do orçamento como moeda de troca de favores políticos através das emendas parlamentares ao orçamento (SODRÉ; ALVES, 2010). Os parlamentares podem apresentar emendas individuais e coletivas ao orçamento, principalmente para a realização de investimentos, ou despesas de capital (ROCHA, 2008; SANTANA, 2011). As emendas individuais seriam as de característica mais clientelista, sendo conhecidas na ciência política como pork barrel (SANTANA, 2011).

O peso das emendas legislativas no total dos investimentos do governo federal foi estimado por Limongi e Figueiredo (2009) em mais de $30 \%$, em média, no período situado entre 1996 e 2001. Os setores mais beneficiados pelas emendas individuais costumam ser os de saúde, educação, infraestrutura e assistência social (SANTANA, 2011). No caso da saúde, o valor dos investimentos feitos com base nas emendas legislativas foi superior aos investimentos originados da proposta do Executivo no mesmo período (LIMONGI; FIGUEIREDO, 2009), O que permite supor uma elevada politização do investimento no SUS.

Nem todos os municípios conseguem se beneficiar dos recursos de emendas parlamentares, pois sua liberação depende da capacidade de elaboração de projetos e da celebração de convênios com o governo federal, o que requer a disponibilidade de quadros técnicos capacitados. Principalmente os municípios de pequeno porte têm maiores dificuldades neste sentido (SANTANA, 2011). E a esta dificuldade deve-se somar a sua baixa capacidade de influenciar diretamente na eleição de deputados, por terem baixo número de eleitores e, consequentemente, por sua baixa capacidade de formar alianças eleitorais com deputados e senadores, capazes de gerarem emendas parlamentares no futuro. Este estudo teve como objetivo analisar como as instituições políticas condicionam o acesso dos usuários de pequenos municípios a serviços de MAC, uma vez que também condicionam a estruturação e a ampliação da oferta destes serviços. 


\section{Métodos}

Foi realizado um estudo de caso sobre a gestão do processo de encaminhamento de usuários do SUS de municípios de pequeno porte para serviços de MAC. Tratou-se, portanto, de um estudo de caráter exploratório e descritivo (GIL, 2009). Por ser estudo de gestão de uma política pública, julgou-se adequado utilizar, no estudo do caso, o ferramental analítico desenvolvido pelo neoinstitucionalismo histórico, que vem sendo usado de forma crescente para a análise de políticas públicas na área social (SKOCPOL, 1995; 1996; PIERSON, 2007), inclusive no Brasil (ARRETCHE, 2005; GERSCHMAN; SANTOS, 2006). Este marco teórico favorece a abordagem analítica das políticas públicas em um contexto histórico concreto, procurando identificar as agendas políticas de cada conjuntura, as arenas políticas em que as decisões são tomadas e os atores envolvidos no processo decisório, que podem se situar dentro ou fora do aparelho do Estado. Um conceito central desta abordagem é o de instituição, definida como regras formais e informais que compõem as opções dos atores sociais (HALL; TAYLOR, 2003; NORTH APUD MARQUES, 1997).

$O$ estudo foi realizado na macrorregião de saúde de Teófilo Otoni (MG), com foco na microrregião de saúde de Almenara (MG) e em um dos seus municípios, Rio do Prado, situado no Vale do Jequitinhonha, nordeste de Minas Gerais. O município tinha 4.506 habitantes em 2010, dos quais $22,9 \%$ tinham renda familiar de até $1 / 4$ de salário mínimo. Apenas seis famílias do mesmo tinham renda superior a mais de cinco salários mínimos (IBGE, 2010), o que sugere uma grande dependência da população local dos serviços do SUS. Nem a macrorregião, nem a microrregião oferecem todos os serviços de MAC necessários às suas populações. De acordo com a Programação Pactuada Integrada (PPI) de Minas Gerais, as demandas para alguns daqueles serviços têm de ser encaminhadas para Teófilo Otoni (MG), sede da macrorregião, e a grande maioria delas, para Belo Horizonte (MG), a quase $800 \mathrm{~km}$ de distância.

Os procedimentos de pesquisa incluíram coleta e análise de dados secundários sobre a rede de serviços de saúde do SUS, entrevistas semiestruturadas que foram elaboradas seguindo um roteiro adaptado a cada tipo de informante, por conta das diferentes experiências, posições e interesses dos mesmos, com lideranças locais (seis) e regionais (quatro). Observação assistemática (SELLTIZ ET AL., 1974) das reuniões da PPI na microrregião, na macrorregião e no Estado, além de análise documental da PPI, do Plano Municipal de Gestão do SUS e do Relatório Anual de Gestão de Rio do Prado. Além das autoridades sanitárias locais, foram entrevistadas autoridades e lideranças do sistema de saúde em Felizburgo $(\mathrm{MG})$, primeira referência para encaminhamento; Almenara (MG), sede da microrregião de saúde); Pedra Azul (MG), sede da Gerência Regional de Saúde; e Teófilo Otoni (MG), responsável pela regulação da Rede de Atenção à Saúde da macrorregião.

Foram coletados e analisados, em primeiro lugar, dados relativos à regionalização do SUS em Minas Gerais, com base em documentos da Secretaria de Estado de Saúde (SES/MG), principalmente o Plano Diretor de Regionalização de Minas Gerais (PDRMG). Também foram coletados e analisados dados obtidos junto à base do Datasus (população residente estimada por macro e microrregiões de saúde). Quanto à oferta de serviços, foram levantados e analisados dados do Cadastro Nacional de Estabelecimentos de Saúde (CNES) a respeito da oferta de serviços hospitalares (unidades e leitos) e de equipamentos por macrorregiões. Para analisar a oferta de consultas e procedimentos especializados de saúde para os moradores de Rio do Prado (MG), foram coletados e analisados dados da base do CNES, disponibilizados pelo Datasus. Todos os dados coletados foram agrupados em categorias e subcategorias de análise, resumidas no quadro 1: 
Quadro 1. Categorias e subcategorias de análise, e suas definições

\begin{tabular}{lll}
\hline Categorias & Subcategorias & Definição \\
\hline $\begin{array}{ll}\text { Estrutura da rede } \\
\text { serviços }\end{array}$ & Oferta de serviços & Serviços de MAC existentes regionalmente \\
& Demanda de serviços & Serviços de MAC mais demandados regionalmente \\
& $\begin{array}{l}\text { Critérios ou parâmetros do } \\
\text { planejamento da rede }\end{array}$ & $\begin{array}{l}\text { Utilização ou não de critérios de planejamento da oferta } \\
\text { regional dos serviços }\end{array}$ \\
& Ampliação de capacidade & $\begin{array}{l}\text { Iniciativas ou não de investimentos na ampliação da oferta } \\
\text { regional dos serviços }\end{array}$ \\
PPI e encaminhamento pases para a programação & $\begin{array}{l}\text { Critérios formais utilizados para a programação pactuada e } \\
\text { integrada }\end{array}$ \\
& Processo de pactuação & $\begin{array}{l}\text { Processo efetivo de pactuação e encaminhamento de pacien- } \\
\text { tes para os serviços de MAC }\end{array}$ \\
& Corporativismo & Influência de interesses corporativos na oferta de serviços \\
Clientelismo local & Influência de interesses clientelísticos no encaminhamento \\
\hline
\end{tabular}

Fonte: Elaboração própria

\section{Resultados}

\section{Estruturação da rede de serviços}

Como o Município de Rio do Prado (MG) só oferece serviços de atenção primária ou básica, toda a sua demanda de procedimentos de MAC tem de ser encaminhada para outros municípios. A primeira referência é o Hospital de Felizburgo, distante 27,4 km, com deslocamento de apenas 40 minutos. De acordo com os gestores da rede entrevistados, o hospital só oferece clínica médica e alguns exames de imagem (ultrassonografia e raios $\mathrm{x}$ ), e de análises clínicas. As gestações de alto risco são acompanhadas em Jequitinhonha (MG), a $117 \mathrm{~km}$ de distância, percurso que toma duas horas de viagem. Os partos são realizados em Felizburgo (MG) ou Almenara (MG), conforme o risco, porém o hospital de referência para gestação de alto risco, que fica em Almenara (MG) não possui Unidades de Terapia Intensiva Neonatal ou de Adulto.

Dependendo da necessidade, os usuários de Rio do Prado (MG) são encaminhados para Almenara (MG), segunda referência e sede da microrregião. $\mathrm{O}$ trajeto entre as duas cidades pode ser feito em rodovia asfaltada ou de terra. No primeiro caso, a distância é de $116 \mathrm{~km}$ e exige $2 \mathrm{~h} 30 \mathrm{~m}$ para ser percorrida; já o segundo trajeto dista $67 \mathrm{~km}$, mas exige tempo semelhante e implica em maior desconforto para os pacientes. Como o encaminhamento dos pacientes é de responsabilidade do município de origem, quando um caso grave chega à Almenara (MG) e os serviços lá existentes não têm capacidade de atendê-lo, ele necessita retornar ao município de origem para novo encaminhamento, aumentando o seu sofrimento, além dos custos com tratamento fora do domicílio. A Lei Orgânica da Saúde (BRASIL, 1990) estabeleceu a descentralização dos serviços para os municípios, e a regionalização e hierarquização da rede de serviços de saúde, porém não definiu de quem é a responsabilidade sobre o sistema, o que ocasiona esta ruptura no atendimento dos usuários.

Segundo os entrevistados, Almenara (MG) oferece apenas as seguintes consultas especializadas: oftalmologia, cardiologia, dermatologia, endocrinologia, nefrologia, neurologia, ortopedia, pediatria, psiquiatria e urologia. Nos casos de cirurgias, somente 
realiza as gerais. E oferece os seguintes serviços de apoio diagnóstico: raios $\mathrm{x}$, tomografia e ultrassonografia. Todos os demais casos devem ser encaminhados para outras referências mais distantes. Jequitinhonha (MG) é a referência seguinte para gestação de alto risco e para tratamento de hipertensos, diabéticos e obesos, com complicações Programa Hiperdia da Secretaria de Estado de Saúde (MINAS GERAIS, 2008-2011).

Tanto a macrorregião Teófilo Otoni (MG) quanto a microrregião Almenara (MG) oferecem poucas cirurgias especializadas. Desta forma, a maior parte da demanda é encaminhada para Belo Horizonte (MG). Outros serviços de MAC também têm de ser encaminhados para a mesma cidade, que dista mais de $700 \mathrm{~km}$ de Rio do Prado (MG), em uma viagem de $10 \mathrm{~h} 30 \mathrm{~m}$, de alto custo tanto para a Secretaria Municipal de Saúde (SMS) quanto para o usuário. A pactuação dos serviços de MAC não está em conformidade com o Plano Diretor de Regionalização de Minas Gerias (PDR/MG), que define que a microrregião de saúde deve ofertar todos os serviços de Média Complexidade e a macrorregião, todos os serviços de Alta. Procurando fortalecer a regionalização da rede SUS e garantir a integralidade da assistência, a Norma Operacional de Assistência à Saúde $\mathrm{n}^{\mathrm{o}}$ 01/2001 (Noas), publicada pela Portaria GM/MS no 95/2001 (BRASIL, 2001), enfatizou o planejamento regional da rede, buscando a organização integrada do sistema em todos os níveis de atenção. Porém, de acordo com todos os gestores da rede entrevistados, isto não acontece porque a capacidade instalada na região é insuficiente.

Não é difícil depreender que o encaminhamento para um município tão distante e tão sobrecarregado dificulta o atendimento e o deslocamento dos pacientes de Rio do Prado (MG).

O financiamento para tais encaminhamentos é feito através da rubrica Tratamento Fora do Domicílio (TFD), instituído pela Portaria SAS/MS n ${ }^{\circ}$ 55/1999 (BRASIL, 1999), que regula a concessão de financiamento para passagens de ida e volta, ajuda de custo para alimentação e hospedagem, inclusive para o acompanhante, para tratamento ambulatorial ou hospitalar previamente agendado. Como há um grande movimento de encaminhamento de pacientes para outros municípios e a demanda excede a oferta, tais dificuldades facilitam a intermediação clientelista dos mesmos, através da interferência na ordem dos encaminhamentos e na distribuição dos recursos do TFD.

O levantamento da rede SUS em Minas Gerais revelou que a oferta de serviços de MAC é dominada pelo setor privado, que detém dos recursos disponíveis para o SUS, por exemplo: $72,3 \%$ dos leitos de internação do Estado e $78,6 \%$ da macrorregião estudada; $89,1 \%$ dos equipamentos de ressonância magnética do Estado e 100\% da macrorregião; assim como $87,9 \%$ dos equipamentos de tomografia computadorizada do Estado e $100 \%$ da macrorregião (BRASIL, 2012). A observação e as entrevistas permitiram constatar que os recursos da PPI são insuficientes para atender a demanda de serviços de MAC de Rio do Prado (MG). A demanda por serviços de cardiologia, por exemplo, que está relacionada à principal causa de mortalidade no País, é de 30 consultas/mês, enquanto a PPI só oferece 2 consultas. Como os serviços existentes na microrregião são privados e contratados apenas para atender o programado na PPI, o Município tem de comprar, a preço de mercado, as 28 consultas que faltam para atender a demanda, ou $93,3 \%$ do total. A contratação desses serviços abre espaço para novas intermediações de cunho clientelista.

A rede de serviços do SUS tem se expandido lentamente, tanto na macrorregião quanto na microrregião. Essa expansão lenta da rede está relacionada à escassez de recursos humanos, principalmente especialistas médicos. Quanto à escassez de recursos tecnológicos, esta não constitui fator de atração e fixação de especialistas médicos na área. Já a escassez de profissionais médicos 
aumenta o poder de barganha dos mesmos nas negociações com os municípios em torno dos preços dos seus serviços. Este problema também abre espaço para o clientelismo nas contratações. Da mesma forma, ocorre uma alta rotatividade dos médicos de família no município em questão. De acordo com as autoridades locais entrevistadas, muitos desses profissionais apresentaram dificuldades para aderir ao mandonismo local no atendimento e no encaminhamento dos usuários aos serviços de MAC.

Um problema sério, que dificulta a ampliação da capacidade de atendimento, é o fato de não haver representação regional nos legislativos estadual e federal. Sem representantes, há dificuldade para a obtenção de recursos de investimentos, oriundos de emendas parlamentares, que, como foi visto, têm uma importância cada vez maior nos investimentos do SUS e são instrumentos de troca de favores no cenário político brasileiro. A ausência de representantes resulta do fato de que, nas eleições para cargos estaduais e federais, costuma haver disputa política entre as lideranças dos diferentes municípios, o que dispersa os votos, já relativamente escassos, em função da pequena dimensão do eleitorado local. Isto mostra que, se na região o clientelismo local desempenha um papel importante nos encaminhamentos e nas contratações de serviços de saúde, o mesmo não acontece em relação à capacidade da região de se inserir nas negociações clientelistas maiores, nas esferas estadual e nacional, a fim de obter emendas parlamentares para investimentos na saúde.

\section{O contexto político local}

De acordo com os entrevistados, o ambiente político de Rio do Prado (MG) é dominado por dois partidos, que vêm se alternando no poder há pelo menos 16 anos: o Partido do Movimento Democrático Brasileiro (PMDB) e o Partido da Social Democracia Brasileira (PSDB), conhecidos, respectivamente e popularmente, por 'Pé de Boi' e 'Pé de Cana'. $\mathrm{O}$ 'Pé de Boi' é tido como representante dos grandes fazendeiros, quase sempre pecuaristas, e de seus clientes políticos. Já a alcunha 'Pé de Cana' deve-se a uma história local, sobre um ex-prefeito daquele partido, que gostava muito de beber socialmente com seus eleitores. A cidade é muito dividida entre os dois grupos: nas eleições de 2008, o 'Pé de Boi' ganhou por apenas quatro votos, o que motivou o 'Pé de Cana' a entrar com uma ação na justiça, denunciando a compra de votos, para tentar reverter os resultados. A composição da Câmara de Vereadores expressa essa divisão: até o final do seu primeiro mandato (dezembro/2012), o prefeito atual - que pertence ao 'Pé de Boi' - contava com uma minoria de aliados na Câmara de Vereadores (quatro do PMDB contra cinco do PSDB), situação que foi revertida na eleição passada. Nesta última eleição, o prefeito não só se reelegeu, como conseguiu fazer maioria absoluta na Câmara.

A sociedade local possui poucas organizações representativas, apenas dois sindicatos: o dos Trabalhadores Rurais e o dos Trabalhadores Municipais, este existente desde 2008. Segundo os entrevistados, sua criação decorreu da necessidade dos funcionários municipais se defenderem do favoritismo, ou clientelismo, existente na prefeitura, que é o maior órgão empregador local. A criação do sindicato representou uma tentativa de organização independente da sociedade, porém houve relatos de perseguições políticas às suas lideranças, que levaram ao afastamento das mesmas e ao consequente esvaziamento da organização. O Sindicato dos Trabalhadores Rurais não goza de boa imagem na sociedade, nem de muita legitimidade. Há diversas denúncias de práticas irregulares do mesmo em relação à previdência social, tais como a cobrança indevida de taxa para a averbação da contagem do tempo para a aposentadoria de trabalhadores efetivos.

Outra organização que vem servindo de 
canal de expressão para setores da população, especialmente os mais pobres, é a Igreja Católica. Segundo os entrevistados, o pároco costuma falar sobre os direitos de cidadania da população nas missas e procura sensibilizar os católicos a não venderem os seus votos nas eleições, o que seria comum no município. A Igreja também realiza campanhas para arrecadar fundos a fim de ajudar no TFD, buscando reduzir a intermediação clientelista deste tipo de encaminhamento para serviços de MAC. No período de desenvolvimento da pesquisa, circulavam diversas cartas anônimas com denúncias de clientelismo nos encaminhamentos para serviços de saúde. Segundo um entrevistado, essa prática constituiria a única forma de denúncia disponível para a sociedade, pois a imprensa da região não costuma divulgar problemas relativos à administração pública local.

As entrevistas realizadas indicaram a existência de longas filas de espera para a realização de procedimentos de MAC, porém não foi relatado o tempo médio dessa espera nem o percentual de usuários que não tiveram acesso a esses serviços; assim como esquemas de favorecimentos de aliados de políticos da situação, típicos do esquema clientelista. Os critérios para a definição da ordem de encaminhamento dos pacientes para os serviços de MAC seriam políticos, de favorecimento aos clientes. Segundo informações da Secretaria Municipal de Saúde (SMS) de Rio do Prado (MG), é realizada uma triagem para oferecer o benefício TFD para quem realmente necessita dessa ajuda. Entretanto, para um ator local entrevistado, este benefício é distribuído seguindo critérios políticos. Até mesmo a ajuda para o transporte e a hospedagem de pacientes e acompanhantes em municípios distantes seriam alvo de barganhas políticas de tipo clientelista, intermediadas por integrantes tanto do Executivo, quanto do Legislativo.

\section{Discussão e conclusões}

A motivação para desenvolver este trabalho partiu da constatação das dificuldades dos usuários do SUS, dos municípios de pequeno porte, em ter acesso a serviços de MAC. O município de Rio do Prado (MG) é de pequeno porte, como $70 \%$ dos municípios brasileiros; faz parte de uma das regiões mais carentes do País, o Vale do Jequitinhonha; sua macrorregião (Nordeste) tem a menor renda domiciliar per capita do Estado (58\% da média estadual); e quase a totalidade de seus habitantes (97\%) depende unicamente do SUS para o acesso a serviços de saúde (BRASIL, 2013).

A microrregião de Almenara (MG) oferece poucos serviços de Média Complexidade, assim como a macrorregião Nordeste, em Teófilo Otoni (MG), não oferece todos os serviços de Alta complexidade. Pela PPI do Estado de Minas Gerais, a maioria destes serviços é encaminhada para a capital (macrorregião Centro), que já responde pelos serviços de MAC dos seus 102 municípios.

A PPI não consegue suprir toda a demanda dos serviços de Média Complexidade - principalmente, as consultas especializadas - de Rio do Prado (MG), necessitando o município contratar, com recurso próprio, médicos para atenderem mensalmente seus habitantes. Como existe uma carência muito grande de especialistas médicos, a falta de oferta com recursos negociados na PPI fortalece o poder de barganha desses profissionais, que conseguem impor preços por seus serviços acima do valor da tabela SUS, mostrando que as regras formais do SUS são suplantadas pelas regras informais. A análise das entrevistas e documentos procurou identificar as principais instituições, arenas decisórias e os atores que participam do processo, levando em consideração a história recente do município no período escolhido para o estudo. A figura 1 ilustra de forma significativa o que foi encontrado. 
Figura 1. Esquema representativo das instituições e atores sociais envolvidos na gestão do encaminhamento de pacientes para média e alta complexidade no Município de Rio do Prado (MG)

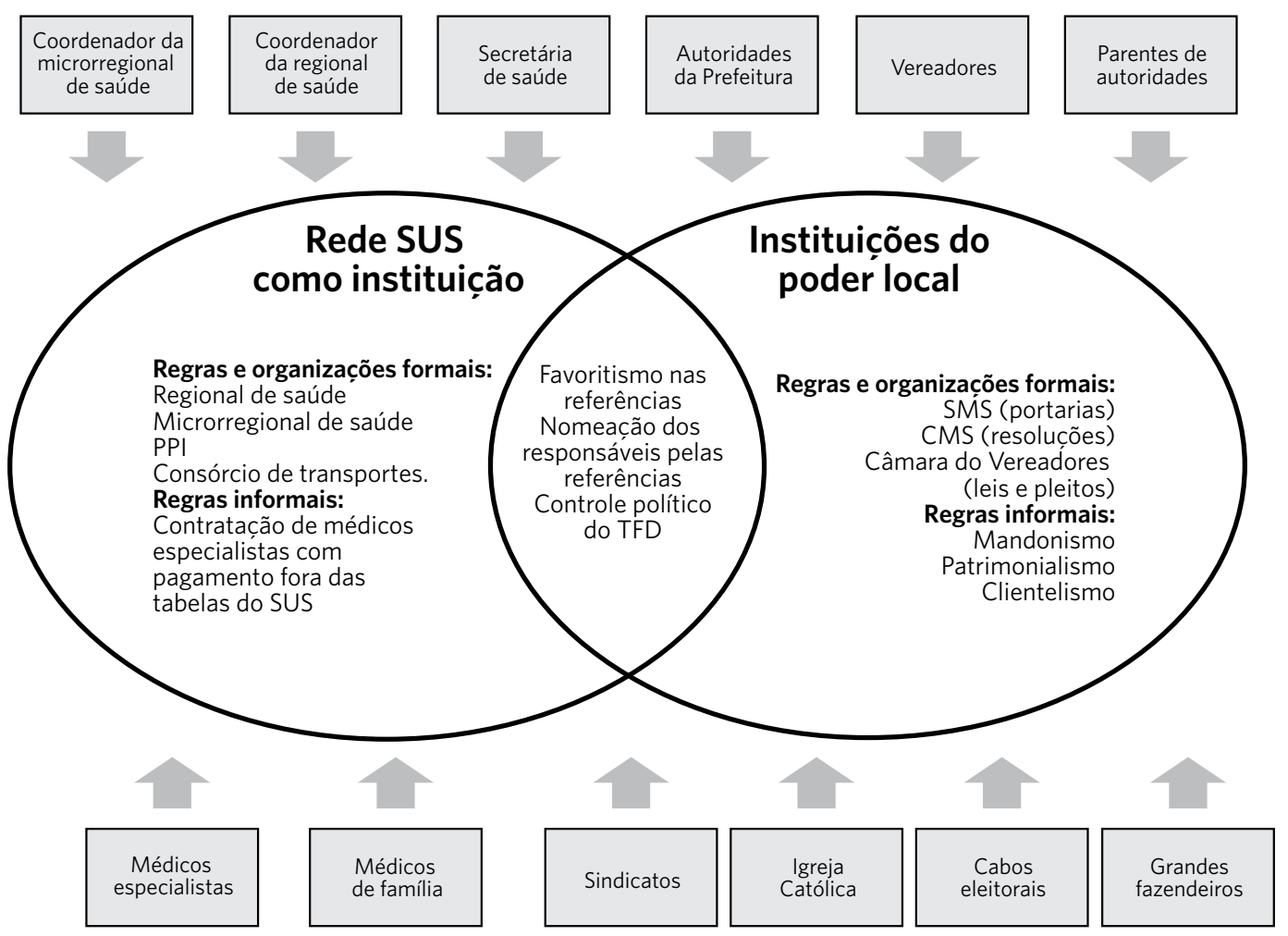

Fonte: Elaboração própria

Ao analisar as relações entre as instituições do poder municipal local e o processo de encaminhamento dos pacientes para serviços de MAC do SUS em Rio do Prado (MG), foi possível observar que existe uma grande influência do poder local na fila de encaminhamento do SUS em benefício de pessoas próximas aos poderosos. Tal situação indica não só uma sobrevivência do mandonismo e do clientelismo local, mas sua interferência sobre o SUS. Onde a oferta dos serviços de saúde e o apoio do TFD são selecionados de acordo a gramática do clientelismo, geralmente quem recebe são eleitores, servidores ou parentes do gestor municipal, que não necessitam desse apoio. Também a garantia do atendimento pelo SUS é usada como barganha na compra de votos, ou o contrário: o não atendimento é utilizado para perseguir adversários políticos, mostrando novamente que existe um predomínio das regras informais sobre as formais e que, no município de Rio do Prado (MG), a gramática do universalismo de procedimentos é esmagada pela gramática do clientelismo.

A municipalização da saúde no Brasil foi feita sob o pressuposto da democratização; associava-se a ideia da descentralização à expectativa de maior controle da sociedade sobre a política e os serviços de saúde (PERES, 2002). As características dos municípios brasileiros e a forma como o poder é exercido nos mesmos, além das relações interfederativas que mantêm com os estados e a União, fazem com que os resultados da municipalização tenham ficado distantes, entretanto, 
dos propósitos originais dos objetivos pretendidos com a descentralização do SUS, e dificultam a gestão da rede de ações e serviços de saúde.

Para a população dos pequenos municípios, como no caso estudado, carentes sob o ponto de vista socioeconômico, as situações acima resumidas dificultam a garantia da continuidade dos cuidados à saúde. Como esta acaba sendo feita em locais distantes, envolve outras questões, como o apoio logístico - transporte, alimentação e hospedagem para usuários e acompanhantes -, que também são passíveis de exploração política. Já que a população da área estudada depende praticamente de forma exclusiva do SUS, ela é mais vulnerável aos interesses oligárquicos e privados. A predominância da gramática clientelista no interior do País, entretanto, favorece o controle privado dos bens públicos e a nomeação de amigos e parentes para cargos públicos, além do favoritismo no acesso a serviços públicos, em função de interesses político-eleitorais, em detrimento dos direitos de cidadania. Desta forma, as oportunidades são oferecidas muitas vezes de forma prioritária para os eleitores ou financiadores das eleições. Uma das dificuldades apresentadas para a ampliação da capacidade instalada, tanto da macrorregião quanto da microrregião de saúde estudadas, foi a inexistência de uma representação da mesma nos legislativos, estadual ou federal, o que dificulta a obtenção de investimentos na forma das emendas orçamentárias parlamentares para a região. Como o sistema político brasileiro comporta um grande número de partidos e o presidente da república não consegue contar com uma maioria clara no Legislativo, ele necessita constantemente construir coalizões para conseguir aprovar suas propostas de governo, em um sistema chamado de presidencialismo de coalização. As emendas orçamentárias parlamentares - principalmente, as individuais - são algumas das ferramentas usadas na busca desse apoio político através das relações clientelistas que estão cada vez mais investindo na saúde. No entanto, os parlamentares investem nas suas regiões de origem, ou nas regiões que apresentam maior número de eleitores, o que não é o caso da região estudada, que não consegue eleger candidatos da região, ficando sem acesso aos recursos das emendas. Um tema importante para futuras pesquisas é a análise dessa relação entre o sistema político e a rede de serviços do SUS. 


\section{Referências}

ARRETCHE, M. A política da política de saúde no Brasil. In: LIMA, N. T. et al. Saúde e democracia: história e perspectivas do SUS. Rio de Janeiro, Fiocruz, 2005. p. 285-306.

ARRETCHE, M.; RODDEN, J. Política distributiva na federação: estratégias eleitorais, barganhas legislativas e coalizões de governo. Dados, Rio de Janeiro, v. 47, n. 3 , p. $549-576,2004$.

BRASIL. Ministério da Saúde. Departamento de Informática do SUS (DATASUS). População Residente - Brasil. População residente segundo Município. 2010. Disponível em: <http://tabnet.datasus.gov.br/cgi/ deftohtm.exe?ibge/cnv/popbr.def $>$. Acesso em: 01 nov. 2011.

Ministério da Saúde. Departamento de Informática do SUS (DATASUS) Agência Nacional de Saúde Suplementar. Beneficiários por Município, Assistência Médica por Município. 2012. Disponível em: <http://www.ans.gov.br/anstabnet/anstabnet/ deftohtm.exe?anstabnet/dados/TABNET_02.DEF>. Acesso em: 19 jan. 13.

Ministério da Saúde. Lei no 8.080, de 19 de setembro de 1990. Dispõe sobre as condições para a promoção, proteção e recuperação da saúde, a organização e o funcionamento dos serviços correspondentes e dá outras providências. Diário Oficial [da] União, Brasília, DF, p. 18055, 20 set. 1990.

Ministério da Saúde. Secretaria de Assistência à Saúde. Portaria $S A S / M S, N^{\circ} 55$, de 24 de fevereiro de 1999. Dispõe sobre a rotina do Tratamento Fora de Domicílio no Sistema Único de Saúde - SUS, com inclusão dos procedimentos específicos na tabela de procedimentos do Sistema de Informações Ambulatoriais do SIA/SUS e dá outras providências. 1999. Disponível em: <http://dtr2001.saude.gov.br/sas/ PORTARIAS/Port99/PT-055.html>. Acesso em: 14 nov. 2014.

Regionalização da assistência à saúde: aprofundando a descentralização com eqüidade no acesso: Norma Operacional da Assistência à Saúde: NOAS-SUS 01/01 e Portaria MS/GM n ${ }^{\circ}$ 95, de 26 de janeiro de 2001 e regulamentação complementar. Brasília: Ministério da Saúde, 2001. (Normas e Manuais Técnicos, Série A).

Cadastro Nacional de Estabelecimentos de Saúde (CNES). Recursos Físicos - Hospitalar - Leitos de internação - Minas Gerais. Disponível em: <http:// tabnet.datasus.gov.br/cgi/deftohtm.exe?cnes/cnv/ leiintmg.def>. Acesso em: 19 dez. 2012a.

Recursos Físicos - Equipamentos - Minas

Gerais. Disponível em: <http://tabnet.datasus.gov.br/ cgi/deftohtm.exe?cnes/cnv/equipomg.def $>$. Acesso em: 19 dez. 2012b.

CARVALHO, J. M. Mandonismo, coronelismo, clientelismo: uma discussão conceitual. Dados, Rio de Janeiro, v. 40, n. 2, p. 1-4, 1997. Disponível em: <http://www.scielo.br/scielo.php?script=sci arttext\&pid=S0011-52581997000200003\&lng=en\&nrm =iso>. Acesso em: 31 mar. 2012.

FAORO, R. Os donos do poder: formação do patronato político brasileiro. São Paulo: Editora Globo, 2001.

GERSCHMAN, S.; SANTOS, M. A. B. O Sistema Único de Saúde como desdobramento das políticas de saúde do século XX. Revista Brasileira de Ciências Sociais, São Paulo, v. 21, n. 61, p. 177-190, jun. 2006.

GIL, A. C. Estudo de caso. São Paulo: Atlas, 2009.

HALL, P. A.; TAYLOR, R. C. R. As três versões do neo Institucionalismo. Lua Nova, São Paulo, n. 58, p. 194$223,2003$.

INSTITUTO BRASILEIRO DE GEOGRAFIA E ESTATÍSTICA (IBGE). Resultados preliminares do Censo Demográfico de 2010. Disponível em: <http:// www.ibge.gov.br/cidadesat/topwindow.htm?1>. Acesso em 13 out. 2011. 
IZECKSOHN, V. A guerra do Paraguai. In: GRINBERG, K.; SALLES, R. O Brasil imperial. Rio de Janeiro: Civilização Brasileira, 2009. v. 2. p. 385-424.

LEAL, V. N. Coronelismo enxada e voto: o município e o regime representativo no Brasil. Rio de Janeiro: Nova Fronteira, 1997.

LIMONGI, F. Presidencialismo, coalizão partidária e processo decisório. Novos estud. - CEBRAP, n. 76, p. 17-41, nov. 2006.

LIMONGI, F.; FIGUEIREDO, A. Poder de agenda e políticas substantivas. São Paulo: USP, 2009. Disponível em: <http://svr-web.fflch.usp.br/dcp/assets/docs/ Limongi/Poder_de_Agenda_e_Politicas_Substantivas. pdf $>$. Acesso em 28 ago. 2012.

MARQUES, E. C. Notas críticas à literatura sobre Estado, políticas estatais e atores políticos. Revista Brasileira de Informação Bibliográfica em Ciências Sociais, Rio de Janeiro, v. 43, p. 67-102, 1997.

MINAS GERAIS. Secretaria de Estado de Saúde. Plano Estadual de Saúde. Belo Horizonte: Secretaria de Estado de Saúde, 2008-2011.

NUNES, E. O. A gramática política do Brasil, clientelismo, corporativismo e insulamento burocrático. Rio de Janeiro: Garamond, 2010.

PERES, A. M. A. M. A municipalização é o caminho? 2001. Dissertação (Mestrado em Saúde Coletiva). Instituto de Medicina Social, Universidade do Estado do Rio de Janeiro, 2001.

PIERSON, C. Beyond the Welfare State? The new political economy of welfare. Pennsylvania: The Pennsylvania State University Press, 2007.
ROCHA, A. S. C. As partes e o todo: Congresso Nacional, executivo e o problema do orçamento no Brasil. Perspectivas, São Paulo, v. 34, p. 55-78, 2008.

RODRIGUES, P. H. A.; SANTOS, I. S. Saúde e cidadania: uma visão histórica e comparada do SUS. São Paulo: Editora Atheneu, 2011.

Gestão Municipal. Rio de Janeiro: Fundação Getúlio Vargas/FGV Management, 2011, 84 p. (Apostila do curso de MBA em Planejamento, Orçamento e Gestão Pública).

SANTANA, V. L. Atraindo o Pork: que fatores explicam a execução das emendas orçamentárias no Brasil? 2011. 85 f. Dissertação (Mestrado em Ciência Política). Instituto de Ciência Política, Universidade de Brasília, 2011.

SELLTIZ, C. et al. Métodos de pesquisa nas relações sociais. São Paulo: Editora Herder, 1974.

SKOCPOL, T. Social policy in the United States, future possibilities in historical perspective. Princeton: Princeton University Press, 1995.

SODRÉ, A. C. A.; ALVES, M. F. C. Relação entre emendas parlamentares e corrupção municipal no Brasil: estudo dos relatórios do Programa de Fiscalização da Controladoria-Geral da União. Revista de Administração Contemporânea, Curitiba, v. 14, n. 3, p. 414-433, 2010.

ZIMMERMANN, A. Teoria geral do federalismo democrático. Rio de Janeiro: Lumen Juris, 1999.

\footnotetext{
Recebido para publicação em abril de 2014

Versão final em outubro de 2014

Conflito de interesses: inexistente

Suporte financeiro: não houve
} 